\title{
Research on Causes and Coping Strategies of Separation Anxiety of Infants in Preschool
}

\author{
Lina Zhang \\ Teachers’ College Shenyang University \\ Shenyang, China
}

\author{
Meijia Dong \\ Sun International Kindergarten Tiexi District \\ Shenyang, China
}

\begin{abstract}
In order to make smoothly transition from family to preschool for infants and increase their adaptability to preschool, this paper adopts methods of observation and interview to analyze the manifestation and causes of separation anxiety of infants in preschool and comes up with corresponding solutions from the aspects of preschool teachers, families and preschool, that is it should enrich teachers' teaching experience and improve their educational and teaching ability; it should cultivate the independence of infants and train their communicative ability; it should create harmonious family environment and correct parents' educational concepts; it should establish the system to prepare infants for preschool and visit families of new infants, thus better solving separation anxiety of infants in preschool.
\end{abstract}

Keywords_Infant, separation anxiety, cause, strategy

\section{OVERVIEW OF SEPARATION ANXIETY OF INFANTS IN} PRESCHOOL

\section{A. Definition of the concept}

The separation anxiety of infants in preschool refers to the problems such as emotional depression, crying, missing family and no sense of belonging caused by their inadaptability to the collective environment of preschool accompanied by separation from their parents after they enter the preschool [1].

\section{B. Analysis of the significance of separation anxiety of infants in preschool}

Separation anxiety of infants in preschool is a normal phenomenon. When infants experience separation anxiety, some may display physiological discomfort such as lack of appetite, sleepless, cough, fever, etc.; some may display psychological emotion problems such as coward, fear, nervous, solitary, etc.; some may have behavioral problems such as crying, behavioral disorder, quarrelling with their partners or indiscipline, etc. All these problems might cause irreparable consequences to the cultivation of their behavioral habit and the development of intellectual personality if not guided properly. Therefore, it can not only guarantee the healthy growth of infants physiologically and psychologically, but also promote to some extent the progress of educational environment and concept in preschool to research and analyze separation anxiety of infants in preschool.

\section{MANIFESTATION OF SEPARATION ANXIETY OF INFANTS}

When infants start their preschool, their separation anxiety manifests in many different forms such as attachment to families, silence, inseparable from their familiar people, refusal of assistance and so forth. This paper analyzes different forms of separation anxiety of infants through detailed cases.

\section{A. Attachment to families}

Case 1: Xiaoming experienced very severe separation anxiety when he started preschool. As soon as his mother is out of his sight, he lies on the ground and cries. Teachers have to let his mother come back. And as long as his mother come back to pick up him, he stops crying immediately and performs very well.

When they start their life in preschool, infants display excessive attachment to their families. Thus, they may cry a lot when their families leave. Prolonged crying will lead to husky voice, even vomit. Teachers should pay close attention to personality and behavior characteristics of each infant before their preschool, take good care of their bodies and offer different ways of help to each infant.

\section{B. Silence}

Case 2: Lanlan, an infant in junior class, has severe separation anxiety. She is introverted and not good at expressing herself. When she is anxious, she is alone, silent or crying.

When introverted infants face with new environment, they will have strong emotional reaction. But they usually will not show this kind of emotion. They cry silently and won't communicate with other infants and teachers. They are often dull, and sometimes have trouble sleeping, either awakening from nightmare or having difficulty falling asleep.

\section{Inseparable from their familiar people.}

Case 3: Xinxin, an infant in middle class, has separation anxiety problem in preschool. He is inseparable from his teachers. He follows his most familiar teacher Miss Liu closely whether in indoor and outdoor activities, or in daily life such as having meals, going to washroom, taking naps, etc. Once Miss Liu leaves for more than a certain period of time, Xinxin will be nervous and cry until she comes back. 
Some infants may closely follow the teacher who has frequent communication with or especially attach to the teacher who is the first to receive them in their first day to preschool. For example, they have to find a special teacher for help when taking naps, going to washroom or drinking water. They need this teacher to feed for them and closely follow them when doing activities. As long as the teacher leaves, they are very anxious.

\section{Refusal of assistance}

Case 4: Lele, an infant in senior class, has attended preschool for over two years, but he is still anxious to go to preschool to certain extent. In daily teaching and activities, Lele shows very dissocial character both in game and teaching. He has little communication with other infants, even if teachers want to help him, he doesn't unnecessarily recognize them [3].

The reason why Lele is unwilling to communicate with others and refuse people's help in this case is that it is hard for him to trust other infants and teachers and integrate to the collective life in preschool. He lacks of safety in preschool, thus causing anxiety.

\section{CAUSES OF SEPARATION ANXIETY OF INFANT IN PRESCHOOL}

\section{A. Infants factor}

When they just start their life in preschool, they are in a totally strange environment with extremely strange partners and teachers around them. They are controlled by a series of regulations and disciplines in preschool instead of unconstraint at home, which often makes them unable to adapt. In addition, it still requires a period of time for infants to leave parents and establish trust or dependent relation with teachers, which usually makes them feel anxious and helpless. Facing with these pressures, infants will show separation anxiety in preschool and build a kind of psychological defense, which means that they enter the self-protection mode, and express strong fear and self-protection awareness to the external environment and people [4].

\section{B. Family factor}

\section{1) Parenting pattern}

Doting parenting pattern often makes children form selfish and unruly habit. This type of infants lacks confidence and their will are so vulnerable that it is very easy to have separation anxiety. Authoritarian parenting pattern requires children to do what they say so that the independence and creativity of their children are severely restrained. This type of infants is not good at making friends and expressing themselves and very careful in everything. And it is difficult for them to adapt to strange environment and people in preschool.

\section{2) Family structure}

In single parent family, infants are easy to have sense of inferiority. They are not good at communication and expression and fear of crowd. They will feel unsafe and helpless without accompanying of parents in preschool.

\section{3) Parent factor}

Some parents are busy with work, having no time to take care of their children. And they not only do not have parents to accompany, but also their caretakers are often frequently changed, resulting in their lack of sufficient security. Under this circumstance, once they separate from their parents in preschool, they will show relatively intense separation anxiety.

In addition, some parents themselves have anxious emotion, which will have greatly influence on infants in preschool. When infants enter preschool, these parents will worry their children's life in preschool. The anxious expression and worrying emotion at this moment will pass on to infants through delicate children-parent interaction, thus causing infants to have anxious emotion. Under such circumstance, it is necessary for teachers to communicate with parents, give them confidence and help them get over the separation anxiety. Thus, parents' anxious emotion has greatly influence on infants.

\section{Preschool factor}

\section{1) The environment of preschool}

The environment of preschool is just like a silent teacher, quietly playing its unique potential role. For example, the design of colorful walls, which is an important link for infants who just start their life in preschool. If infants see solemn and dignified preschool without vigor and warmth, they will feel mental pressure.

\section{2) Inexperienced teachers}

Experienced teachers can help infants with suitable educational methods to effectively deal with separation anxiety of infants, whereas inexperienced teachers take serious attitude to treat infants, which may make infants feel unhappy in preschool because they believe that their teachers do not love and care for them like their parents, thus having anxious emotion.

\section{STRATEGIES TO RELIEVE SEPARATION ANXIETY OF INFANTS IN PRESCHOOL}

It can help infants relieve separation anxiety to make them integrate into collective life in preschool from the following aspects.

\section{A. It should cultivate the sense of independence of infants}

The sense of independence of infants means that infants can quietly think and understand problems in an independent living space. Infants with sense of independence rarely have bad emotions such as anxiety, anger, testiness, etc. and are much better than other infants in handwork, games and application of knowledge. Therefore, it is of positive significance to cultivate infants' sense of independence to relieve separation anxiety.

\section{B. It should train communicative ability of infants.}

Sharing is Chinese traditional virtue. Infants who know how to share can easily establish a good relationship with their peers in activities. Therefore, in preschool, teachers can encourage infants to exchange toys, books and their favorite 
things with other infants, teach them to share their toys and love and help them integrate into new environment as soon as possible, which can better relieve their separation anxiety.

\section{Family and preschool should work together to encourage infants}

In strange environment, infants' judgment on surroundings is based on their parents' reaction. Such phenomenon is called as "social referencing" in child psychology. Therefore, it should not ignore parents' separation anxiety. As for infants who just start their life in preschool, preschool can show their handworks or photos playing in preschool to parents in opening day so that parents can know what their children do in preschool every day in a direct and real manner, thus relieving their separation anxiety. In addition, parent should actively cooperate with preschool and trust preschool and teachers. Through cooperation between family and preschool, it should encourage infants and help them get rid of separation anxiety.

\section{It should correct parents' educational concepts.}

Democratic family educational concept focuses on communication with infants, respects infants' opinions, put strict demands on them and gives them fully decision-making power. Therefore, democratic educational concept can significantly improve infants' separation anxiety and enable them to adapt to the life in preschool as soon as possible and to behave more naturally and stably when leaving their parents.

\section{E. It should establish the system to prepare infants for preschool}

The system to prepare infants for preschool means that infants are accompanied by teachers and parents to get to know the environment of preschool before starting their life in preschool on an irregular basis [5]. Preschool can arrange specialized teachers to show infants and their parent the facilities and surroundings of preschool and parents can play with their children in preschool in order to make them get familiar with and like preschool as soon as possible and full of curiosity and joy to the preschool.

\section{F. It should establish the system to visit families of new infants}

Through establishing the system to visit families, preschool can not only know family background of infant, life habit, physiological and psychological status very quickly, but also know parents' thoughts and help them relieve their inner worries in order to narrow the distance between teachers and infants and between teachers and parents, let infants and parents get to know teachers and establish sense of trust and familiarity with teachers.

\section{G. It should focus on the creation of environment in preschool}

The environment of preschool is an important factor to attract infants' attention and avoid separation anxiety. Therefore, the environment should be comfortable with warmth. It should decorate classrooms and dormitories as like "home", for example, it can hang infants' family photo and their favorite cartoon image in order to make them feel at home and reduce separation anxiety.

\subsection{It should enrich teachers' teaching experience.}

The teaching experience and educational ability of preschool teachers play a critical role in relieving separation anxiety of infants. Experienced teachers can communicate with infant a lot, take good care of them, get to know their opinions and play with them on an equal footing. By doing so, the distance between teachers and infants can be narrowed and the sound relationship between them can be established, thus infants' obtaining enough confidence and relieving separation anxiety.

\section{CONCLUSION}

It is the common responsibility of families and preschools to ease children's separation anxiety when entering preschools. Therefore, it requires parents to correct their educational concepts and create sound family atmosphere for their children. What preschools need to do is to establish the system to prepare infants for preschools and create homey environment for infants, thus improving the quality of preschool in an allround manner. Preschool teachers should actively guide infants to build sound peer relationship and ease their anxiety through organizing abundant games while respecting individual differences, teaching them according to their aptitude, giving full play to their subjective ability, and finally helping them avoid the occurrence of anxiety in preschool through active cooperation between preschool and family.

\section{REFERENCES}

[1] Lin Qiufeng, Research on the Coping Strategies of Relieving Separation Anxiety of New Students [J]. Shandong Preschool Website, 2013, (2): 91-93.(In Chinese)

[2] Zhu Cuiping, Several Methods to Shorten Adjustment Period for New Students [J]. Early Education, 2014,(9):33-34. (In Chinese)

[3] Luo Zengrang, Research on the Development and Changes of Separation Anxiety of Children [J]. Psychological Development and Education, 2015,(4):93-94. (In Chinese)

[4] She Cuihua, On Causes and Coping Strategies of Separation Anxiety of Infants [J]. Preschool Education, 2016(7):12-13.(In Chinese)

[5] Wei Qinfang, On Cases and Reflection Relieving Separation Anxiety of Infants in Preschool [J]. Preschool Education, 2013(9):11-13.(In Chinese) 